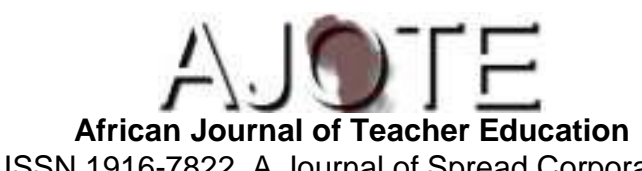

ISSN 1916-7822. A Journal of Spread Corporation

Volume 82019 Pages 238-253

\title{
Exploring the Effectiveness of Informal Apprenticeship in a Community of Practice: A Case Study of Katwe, Kampala-Uganda.
}

\author{
Denis Kintu1 ${ }^{1}$ and Irene Aheisibwe ${ }^{2}$ \\ ${ }^{1}$ Department of Mechanical \& Production Engineering, Kyambogo University \\ P.O Box 01, Kyambogo-Uganda \\ ${ }^{2}$ Department of Foundations of Education, Bishop Stuart University. \\ P.O. Box 09, Mbarara-Uganda.
}

\begin{abstract}
Artisans trained informally in Katwe, a community of practice in Kampala, Uganda are capable of doing various technical tasks such as to operate, service, repair and fabricate various equipment and tools. In this study, we set out to find out the effective methods used for training. We employed a qualitative approach to collect data, analyze and present findings. The methods commonly used in Katwe are; practicing through trial and error, observations, mentoring and coaching, discussions, and by real-world problem-solving. Challenges for Katwe community of practice include: high cost of materials, electricity and little time for training. We concluded that the training methods used can be incorporated in the formal curriculum to improve competence.
\end{abstract}

Keywords: Apprenticeship, Communities of Practice, Working and Learning

\section{INTRODUCTION}

\section{Communities of practice}

Communities of practice are self-organized and selected groups of people who share a common sense of purpose and a desire to learn and know what each other knows (Lave and Wenger, 1991). "Passion, commitment, and identification with the group's expertise" is the glue that holds these groups together (Wenger and Snyder, 2000, p. 139). It is with this group that you learn the intricacies of your job, explore the meaning of your work, and encounters learning on the job as '... an integrated and inseparable aspect of social practice' (Lave \& Wenger, 1991, p. 31). 
Exploring the Effectiveness of Informal Apprenticeship in a Community of Practice: A Case Study of Katwe, Kampala-Uganda

In communities of practice, the transmission of traditional culture and indigenous knowledge has long been operated in the form of informal apprenticeship. Informal learning can take place in any space, such as the workplace, the family, a religious institution, the community and the like; like formal and non-formal learning, informal learning can occur at any age, from birth to death (Schugurensky, 2000). The European Training Foundation (ETF) (2006), observed that traditional/informal apprenticeship is the main entry point for dropouts from education, and also for some graduates from pre-secondary vocational education. This type of training is unregulated and relies largely on kin or personal relationships in which the apprentice is trusted to the master. Normally the apprentice's family pays the master for the right to have the youngster trained. In other cases, apprentices pay for their learning by working for wages lower than that of semi-skilled workers (ETF, 2006). In communities of practice, skills and experiences are communicated from masters to apprentices (Lave and Wenger, 1991). An example of a community of practice is Katwe, found in Kampala-Uganda.

\section{Katwe Community of Practice}

Katwe, located in Makindye Division, is bordered by Nakasero to the north, Nsambya to the east, Kibuye and Makindye to the southeast, Ndeeba to the south and Mengo to the west. The road distance between Kampala's central business district and Katwe is approximately 3 kilometres. At the time of Uganda's Independence from Britain in 1962, Katwe was a center of African ingenuity, where artisans, craftsmen and technicians repaired imported electronics, automobiles, televisions, refrigerators and all kinds of home appliances. The more ingenious of these craftsmen would improvise and "manufacture" imitations of the original articles. The Baganda, an ethnic group in Uganda call such improvised articles Magezi ga Baganda (Wisdom of Baganda) (Lule \& Nambooze, 2006). Over the next half a century, that ingenuity has sharpened, the industry has thrived and taken in more apprentices and the range of articles locally manufactured has increased. In 2007, it was estimated that Katwe employed over 3,000 artisans and metal fabricators in over 800 individual small enterprises, according to Katwe Small Scale Industry Association (KASSIDA), the association under which most enterprises are registered. The Katwe artisans now collaborate with Makerere University's faculty of technology, to take their industry to the next level. Another group that has been traditionally attracted to Katwe are entrepreneurs and independent businesspeople, starting from meager beginnings, who have been viewed as "risky" by Uganda's conservative banking industry. These have included cooked food vendors, wholesalers of local foodstuffs, herbalists and owners of small transportation companies. Other businesspeople who have come to Katwe include vendors of second-hand electronics, and sellers of scrap goods and 
Exploring the Effectiveness of Informal Apprenticeship in a Community of Practice: A Case Study of Katwe, Kampala-Uganda

previously-owned merchandise (wikipedia.org/wiki/Katwe). A lot of apprenticeship takes place alongside working in Katwe, a community of practice. This is manifested from the fact that artisans trained from this community are skilled and competent to carryout various mechanical technical tasks like to operate, service, repair and fabricate various equipment and tools, yet they have not been to any school but learnt on the job (Kitubi, 2019). This is a capability that these researchers have found that artisans from the formal Vocational Training Institutions (VTIs) struggle to achieve.

\section{Problem}

According to UNESCO-UNEVOC (2014), the informal sector in Uganda remains a stronghold of employment, accounting for 58\% of non-agricultural employment in 2011. However, the Technical Vocational Education and Training (TVET) system has largely neglected the specific training needs of the informal sector; there is no systematic approach to skills development for people already in or seeking to enter the informal sector; many of the training offers are supply driven, not based on market assessments and only duplicate formal sector training at very low levels (UNESCO-UNEVOC, 2014). According to the Association for the Development of Education in Africa (ADEA) (2008), in most African countries with a large informal economy like Uganda, informal/ traditional apprenticeship is the most common option available for young people wanting to acquire the vocational skills they need in order to find work, especially for those with a low level of education. In many of these countries, it is even the main system for training young people who are seeking work (ADEA, 2008). In Katwe community of practice, an informal sector in Kampala-Uganda, working and learning is done concurrently. The importance of this community in terms of skills and economic development cannot be underrated. Over the years, informally trained artisans from this community have repaired various equipment and produced artifacts, yet they have not been to any school but learnt on the job (Kitubi, 2019), a capability, which to our knowledge, that artisans from the formal Vocational Training Institutions (VTIs) struggle to achieve. This paper explores the effectiveness of informal apprenticeship in a community of practice. It is based on a research that set out to find out the organization of working/learning activities, effective training/learning methods and the issues affecting the working/learning in Katwe as a community of practice. The paper focuses on the following research questions: -

1. What are the working and learning activities in Katwe as a community of practice?

2. How are the working and learning activities in Katwe as a community of practice organized? 
Exploring the Effectiveness of Informal Apprenticeship in a Community of Practice: A Case Study of Katwe, Kampala-Uganda

3. What are the effective training and learning methods used in Katwe as a community of practice?

4. What are the issues affecting the working and learning activities in Katwe as a community of practice?

\section{THEORETICAL FRAMEWORK}

The theoretical perspective is the philosophical stance informing the methodology and thus providing a context for the process and grounding its logic and criteria (Crotty, 1998). The theories underpinning this research were the sociocultural theories of learning. Sociocultural approaches emphasize the interdependence of social and individual processes in the construction of knowledge (John-steiner \& Mahn, 1996). Whereas much of the background for sociocultural theory was put forward by Lev Vygotsky (1931/1997), additions, elaborations, and refinements of sociocultural theory can be found in works regarding activity theory (Chaiklin \& Lave, 1993) and cultural-historical activity theory (Cole, 1996). Although these theories are not all identical, they share some concerns and beliefs (Wilson \& Peterson, 2006). First is the point that knowledge is inseparable from practice: we know by doing. This means that we need to look at people while they are doing something meaningful-that is, working on authentic problems-if we want to "see" what they know. A second principle of the sociocultural theory is that learning is fundamentally a social phenomenon that takes place within the communities we belong to. These two beliefs lead to the idea that knowledge and learning exist in the interactions between individuals and the contexts in which they live, in the activities we participate in. Thus, "communities of practice" or "learning communities" become critical to learning. A third feature of these theories is that it is within those communities that standards lie. The norms for testing the quality of a performance are determined by groups, not individuals, and one's performance is assessed through genuine participation (Wilson \& Peterson, 2006).

\section{LITERATURE REVIEW}

The International Labour Organization (ILO) (2012), defines informal apprenticeship as a system by which a young learner (the apprentice) acquires the skills for a trade or craft in a micro- or small enterprise learning and working side by side with an experienced craftsperson. Apprentice and master craftsperson conclude a training agreement that is embedded in local norms and traditions of a society. Costs of training are shared between apprentice and master craftsperson (ILO, 2012).

This distinction reflects the socialization of the act of apprenticeship and its evolution from being a family responsibility to being a social responsibility incumbent upon professional organizations (ILO, 
Exploring the Effectiveness of Informal Apprenticeship in a Community of Practice: A Case Study of Katwe, Kampala-Uganda

2012). More comprehensively, De Grip (2015), defined informal learning in the workplace as the acquisition of skills through learning by doing as well as by watching other workers, taking instructions, and receiving supervision or feedback from supervisors or co-workers (De Grip, 2015). The ILO (2012) further observes that informal apprenticeship is not just on-the-job skills development, it is a real form of training featuring rules (the contractual relationship between a master craftsman and an apprentice is guaranteed by social norms and/or the profession) and pedagogy: a process characterized mostly by progress from an introductory phase (observing) to initiation (starting to do), participation (carrying out alongside) and recognition (being able to practice the occupation).

Schugurensky (2000), conceptualized three forms of informal learning. The first is self-directed learning refers to 'learning projects' undertaken by individuals (alone or as part of a group) without the assistance of an 'educator' (teacher, instructor, facilitator), but it can include the presence of a 'resource person' who does not regard herself or himself as an educator. It is both intentional and conscious. It is intentional because the individual has the purpose of learning something even before the learning process begins, and it is conscious, in the sense that the individual is aware that she or he has learned something. The second is incidental learning refers to learning experiences that occur when the learner did not have any previous intention of learning something out of that experience, but after the experience she or he becomes aware that some learning has taken place. Thus, it is unintentional but conscious. The third form is by socialization (also referred to as tacit learning). This refers to the internalization of values, attitudes, behaviors, skills, etc. that occur during everyday life. Not only we have no a priori intention of acquiring them, but we are not aware that we learned something.

The great advantage of these forms of learning is that they offer young people a path into employment (Adams et al, 2013). Furthermore, De Grip (2015) identified the following pros of informal learning: Learning by doing is often an automatic byproduct of productive work; and knowledge spillovers between peers in the workplace contribute to firm productivity. Additionally, HalliDay-Wynes \& Beddie, (2009) propose another advantage of informal learning. In their view, people with minimal school education, poor literacy and numeracy skills, and low self-esteem often lack confidence in their ability to learn in formal settings and, consequently, they can become disengaged from learning. Disengaged learners may have useful skills but are unable to articulate them and build on them therefore informal learning can be a potent means for re-engaging such disengaged learners (HalliDay-Wynes \& Beddie, 2009). 
Exploring the Effectiveness of Informal Apprenticeship in a Community of Practice: A Case Study of Katwe, Kampala-Uganda

However, informal learning is not without shortcomings. De Grip (2015), urges that policymakers neglect informal learning and emphasize formal training courses for lifelong learning because continual technological change alters skill demands. In a similar vein, ILO, (2012) are of the view that informal apprenticeships, which concern a large majority of young people in many African countries, fail to address certain needs, for example there is no access to new skills and technologies (ILO, 2012). Further, De Grip (2015), observes that learning by doing does incur opportunity costs through forgone work time. Therefore, young workers are often expected to pay (part of) these opportunity costs by accepting a lower wage in an apprenticeship, internship, or traineeship position in their first year of employment (De Grip, 2015). The European Training Foundation (ETF) (2006), also highlighted the main limitations of informal apprenticeships. These are:

(i) lack of formal arrangements, which can lead to exploitation of labour;

(ii) limited transfer of knowledge to the apprentice;

(iii) quality issues in the training provided; and

(iv) lack of opportunities for further learning for apprentices. However, despite the limitations of informal apprenticeships, the sector remains important regarding skills development for employability in the informal economy.

For example, in Kenya, the available information indicates that some $40-60 \%$ of informal sector operators acquired their skills through apprenticeships commonly known as 'Jua kali' training. The 'Jua Kali' programme was introduced in Kenya to encourage training in the informal sector (Johanson \& Adams, 2004). The Kenya 'Jua Kali' training programme was successful in its pilot stage in expanding the supply of training to workers in the informal sector and lowering cost. This training programme had positive impact on the earnings of participants and strengthened the capacity of local 'Jua Kali' Associations in Kenya and the development of TVET in the country (Maclean \& Wilson, 2009). The above literature therefore brings out the effectiveness of informal apprenticeship in communities of practice.

\section{METHODOLOGY}

\section{Study design}

The research design was a descriptive survey design. In descriptive research, a researcher begins with a well-defined subject and conducts a study to describe it accurately and the outcome is a detailed picture of the subject, the specific details of a situation, social setting, or relationship; focuses on 
Exploring the Effectiveness of Informal Apprenticeship in a Community of Practice: A Case Study of Katwe, Kampala-Uganda

"how?" and "who?" questions: "How did it happen?" "Who is involved?" (Neuman, 2007). Additionally, Kombo and Tromp (2006) note that a descriptive study design is used to describe the state of affairs, as it exists. It is used when collecting information about people's attitudes, opinions, habits or any of the variety of education or social issues. Many educational study approaches are descriptive because as they only give an account of the conditions or existing relationships and practices that are happening (Cohen and Manion, 1994). The researchers therefore used the descriptive study design because it was deemed suitable to gather data on the effectiveness of informal apprenticeship in Katwe, a community of practice.

\section{Study area}

The study was carried out in Kampala district, the capital city of Uganda-East Africa. This is where the community targeted for the study, Katwe, lies. The researchers sought permission from the Kampala City Council Authority (KCCA) to carry out a study of the area. A reconnaissance trip was made to the area to familiarize the researcher with its operations. Katwe community of practice was deliberately chosen because it is the largest informal community of practice in Uganda with a wide range of informal working and learning activities, the community possesses a rich history in apprenticeships, among other factors. In addition, it was accessible to the researchers without difficulty.

\section{Study population}

The target population of the study consisted of the business owners, the workers, the apprentices, and the administrators of the area.

\section{Sampling procedure}

A total of thirty participants were involved in the study. They included twenty-two males and eight females, mostly from the Baganda ethnic group of central Uganda in the age range of between 15 years to 45 years. They were selected purposively. The only condition applied was that one should have been involved in working and learning activities for at least two months in Katwe. This requirement ensured that the respondent was conversant with all the activities within this setting. The researchers ensured that at least 3 participants were selected from each of the various working and learning activities. 
Exploring the Effectiveness of Informal Apprenticeship in a Community of Practice: A Case Study of Katwe, Kampala-Uganda

\section{Methods of data collection}

The researchers employed three methods for data collection: interviews, observations and documentary analysis. According to Cohen, Manion, and Morrison (2000), interviews involve a two-person conversation initiated by the interviewer to gather data through direct verbal interaction between individuals. On the other hand, observations enable the researchers to understand the context of programmes, to see things that might otherwise be unconsciously missed and to discover things that participants might not freely talk about in interview situations. Questionnaires were deemed unsuitable for the study because of the rigorous nature of work activities in the informal sector and also because most respondents were illiterate.

\section{Interview Method}

In this method, face to face interviews between the researchers and the respondents were carried out using a pre-tested interview guide with open ended questions. The data from the respondents was recorded and later transcribed. The interviews ensured accurate information and allowed deeper investigation into the study problem. Additionally, it enabled the researchers to observe non -verbal communication. Bhandarkar et al. cited in Odiya (2009) classified interviews as focused or clinical. In focused interviews, which were used for the study, attention was focused on a respondent's experience. The researchers had a definite set of topics to be covered and sought a definite type of information. To create a good connection with the respondents, and also because most of them are semi-illiterate, the researchers used the local dialect, Luganda which is also commonly used during the working and learning activities during the interviews. This ensured that the views of each of the respondents were properly articulated.

\section{Observation method}

One of the more obvious ways of gathering data is by observing the culture or environment under study. Consent was sought from the administrators for the researchers to carry out observations of working and learning activities. The observations were done as interviews were being carried out and were recorded. A well-structured observation checklist was used for the study. The observations took place in such a way that the people who were being observed were not aware because if they were, naturally they can change behaviour.

Documentary Analysis 
Exploring the Effectiveness of Informal Apprenticeship in a Community of Practice: A Case Study of Katwe, Kampala-Uganda

Creswell (1994) explains that documents are any written information or physical objects that are analyzed for study to obtain data such as manuals, books, journals, registers, newspapers, letters and minutes. The researchers used documentary analysis method to obtain information on some of the working/learning activities in Katwe community of practice. The documents were got from the administrators.

\section{Validity of the data collection instruments}

The research instruments were validated beforehand by colleagues at our departments. They reviewed and analyzed the contents of the interview guides and observation checklists in order to ascertain that the instruments were suitable for the purpose for which they were designed. They offered suggestions which the researchers used in introducing the necessary corrections and improvements to the instruments.

\section{Data analysis procedure}

Data were analyzed qualitatively. All the data gathered were subjected to content analysis in order to abstract relevant information. This was done by first transcribing all the interview responses, interpreting, and reflecting after every session in the field to identify major themes and put them in categories. This approach to analysis is supported by Creswell (1994) who argues that qualitative data analysis primarily entails classifying things, persons, and events and the properties which characterize them. Furthermore, content analysis delivered a good account into the working and learning activities in Katwe as a community of practice in Uganda.

\section{RESULTS AND DISCUSSION}

\section{Introduction}

The presentation and discussion of findings observed the sequence of the research questions.

\section{What are the working and learning activities in Katwe as a community of practice?}

The first research question sought to identify working and learning activities. From the interviews and observations, we identified the following activities; motor-vehicle and motorcycle mechanics, welding and metal fabrication, foundry technology, electrical and electronics repairs, tailoring, knitting and garments, saloon and barber services, fitting and machining, carpentry and joinery, shoes/leather and restaurant and catering services. These business activities are mostly owned and operated within family lines. It's within the family that knowledge and skills about these activities are transmitted. This is a 
Exploring the Effectiveness of Informal Apprenticeship in a Community of Practice: A Case Study of Katwe, Kampala-Uganda

form of traditional apprenticeship, a system in which skills are transmitted from a father or mother to family members (ILO, 2012). In Europe, prior to industrialization, the learning of occupational skills typically occurred in the family, or in small businesses which served and met the needs of their communities (Billet, 2013).

\section{How are the working and learning activities in Katwe as a community of practice organized?}

This research question sought to clarify how the working and learning activities in Katwe are organised. From the interviews and documents accessed, we found out that most of the trades are under an umbrella organization, Katwe Small Scale Industrial Development Association (KASSIDA). The association controls and organizes most of the activities of registered members. For instance, interested members are selected from various trades to participate in the non-formal skills development programme. This programme is organized every year by Business, Technical, Vocational Education and Training (BTVET) department of the Ministry of Education and Sports (MoES). The major aim of the programme is to further enhance the development of skills of the informal artisans in the various trades. The participants are assessed for competence by the Directorate of Industrial Training (DIT) and awarded a certification document known as workers PAS (Practically Acquired Skills) permit. This is supported by Nilsson (2011), who posits that possession of a certification document which can be shown to others is one of the ways of measuring competence levels of an individual.

We also found out that KASSIDA engages students from various formal vocational training institutions and universities in industrial training/internship activities. Mjelde (1993), points out that learning at workplaces by apprentices places the learner in direct contact with the subject matter as well as with the training supervisors and colleagues. Billet (2001), further emphasises that the types of activities individuals engage in and the guidance they access are central to learning the knowledge required for work. Participation in workplace tasks assists new learning and reinforces what has been learned at school through further practice. Workplaces are seen as legitimate and effective learning environments.

\section{What are the training and learning methods used in Katwe as a community of practice?}

The research question sought to identify the training and learning methods often used in Katwe community of practice. Basing on the observations and interviews carried out, five methods emerged from the working and learning activities. 
Exploring the Effectiveness of Informal Apprenticeship in a Community of Practice: A Case Study of Katwe, Kampala-Uganda

The first type and commonly used method is "learning by practicing through trial and error" until one perfects. One respondent, a turner in one of the enterprises had this to say regarding this method:

'At first, it was a challenge to perfect turning. But senior colleagues encouraged me on. They offered me off cut pieces to practice on. Setting the work on the lathe and taking accurate measurements using vernier calipers were tricky. I would machine under dimensions. I tried several times during off hours until I perfected. I'm now a senior turner in this enterprise' (Personal Communication, March 10, 2018).

According to Billet (2013), across human history, learning through practice (for example, of the skills needed for work) has been the single most important process for developing occupational competence and it has served both societal and personal needs well. A key point for vocational teaching is that a balance needs to be sought between allowing learning through experimentation and trial and error (Wilson \& Peterson, 2006).

The second method "observing from more experienced colleagues" involves learning a new task from a more proficient co-worker or supervisor. One respondent, a welder employed at one of the enterprises had this to say regarding this method:

'When I came here, I would just stand and observe the way my workmates would take measurements, mark out and then cut and join different metal pieces together. I only used to help them by lifting the heavy pieces. Slowly, I learnt taking measurements and cutting using the hacksaw under their observation. Initially, I made errors but they would correct me. They started to trust me and could assign me less complicated tasks. Am a fast learner....after three weeks, I fabricated a window frame unsupervised' (Personal Communication, March 10, 2018).

This supports the social learning theory which recognizes the idea that individuals learn through observing and then imitating others.

The third method "Mentoring and coaching" is another type of learning commonly applied in Katwe. An apprentice of the saloon trade had this to say about this method;

'When I finished my diploma studies in accountancy, I searched for a job but failed to get one. My mother suggested that I come to Katwe and join her saloon business. I had 
Exploring the Effectiveness of Informal Apprenticeship in a Community of Practice: A Case Study of Katwe, Kampala-Uganda

some idea but couldn't plait nicely. When a customer comes, we could plait together with mum as she observes, guides and corrects my errors. I have now mastered the trade and earning money from it' (Personal Communication, March 10, 2018).

Mentoring is often associated with the act of providing guidance, assistance and informal support to less experienced work colleagues and new employees. Support for this notion of mentorship is supported by Spencer (1999), cited in Misko, (2008) who distinguishes the mentor relationship from other forms by noting that it is based on encouragement, constructive comments, openness, mutual trust, respect and a willingness to learn and share.

The fourth method "Learning through discussion" with peers and supervisors was another main method of learning. One respondent, an apprentice of motor vehicle mechanics had this to say regarding this method:

'When a vehicle is brought in for repair, I would listen to customers explain the fault to my senior colleagues but couldn't really tell which part is faulty. Then am requested to bring the toolbox. I slowly started by learning how to identify sizes of the spanners and how to use them before learning the different parts of the vehicle and to diagnose faults and rectify them. My colleagues have been very helpful by explaining to me the procedures to follow. I hope to be a good mechanic soon' (Personal Communication, March 10, 2018).

This is similar to an ethnographic study of apprenticeship learning by Yucatec midwives by Jean Lave and Etienne Wenger (1991), which emphasized the role of conversations about problematic cases. As stories were told by attendees at a birth, other attendees offered similar stories. Together, the stories were packaged as 'situated knowledge'.

The fifth method "Learning by real-world problem-solving". This is another method commonly used in Katwe. Usually, work activities involve services such as repairs, modifications and maintenance which are practically done by the masters alongside apprentices. It's a highly effective means for developing expertise. One respondent, a welder had this to say regarding this method:

'Some days at work, customers would bring broken components like wheelbarrows, motor vehicle parts, metallic molds etc. for repair. I would keenly follow my senior colleagues as they weld back broken component parts together. They would allow me 
Exploring the Effectiveness of Informal Apprenticeship in a Community of Practice: A Case Study of Katwe, Kampala-Uganda

to do the final touches. With time, I participated more and that is how I became a good welder.' (Personal Communication, March 10, 2018).

'Problem based learning' is an enquiry-based approach to problem solving that grew out of medical education. It is intuitively appealing as a way of developing knowledge in the context of vocational education (Savery \& Duffy, 1995).

\section{What are the issues affecting the working and learning in Katwe as a community of practice?}

This item sought to identify the issues affecting the working and learning activities in Katwe. A number of challenges were identified. The first challenge identified was the high cost of materials and electricity. Regarding this aspect, an enterprise owner lamented;

'The cost of materials keeps fluctuating, I can't have standard prices for my products and my customers keep complaining. Profits have drastically reduced....The electricity tariffs have also escalated and we sometimes experience load shedding, which affects our working and training activities. No one seems to care about us. Even the government has abandoned us' (Personal Communication, March 10, 2018).

The second challenge was that the time availed for training is so little. The third challenge was that the working and training area is small and congested. The forth challenge is that the workers and apprentices lack the necessary personal protective wear, yet they are in constant interaction with workshop safety hazards. The fifth was that the trainees complained of poor remunerations and lack of insurance policies. And the sixth challenge was that it is difficult to attract females in most of these activities because they prefer lighter tasks compared to their male counterparts.

\section{CONCLUSION AND RECOMMENDATIONS}

The main conclusion based on the findings of the study was that some effective training and learning methods in this community of practice such as learning by real-world problem-solving and learning by practicing through trial and error should be incorporated in the formal VTIs curriculum to improve competence levels of graduates from this education sub-sector. Accordingly, the researchers recommend that the formal VTIs should create more linkages with this community to improve on graduates' competence by collaborating on practical training. The government should make decisions and policies that position this community to maximize the benefits and minimize the challenges 
Exploring the Effectiveness of Informal Apprenticeship in a Community of Practice: A Case Study of Katwe, Kampala-Uganda

presented; allocate funding for this community to enable them produce goods that can compete globally and stimulate more training and learning.

\section{REFERENCES}

ADEA (2008). Biennial meeting of the Association for the Development of Education in Africa (ADEA) in Maputo, Mozambique.

Billet, S. (2001). Learning in the workplace: Strategies for effective practice. Crow's Nest: Allen \& Unwin.

Billet, S. (2013). Learning through practice: beyond informal and towards a framework for learning through practice: In (Eds.), revisiting global trends in TVET: Reflections on theory and practice. UNESCO-UNEVOC, Bonn Germany.

Chaiklin, S., \& Lave, J. (1993). Understanding practice: Perspectives on activity and context. Cambridge, England: Cambridge University Press.

Cohen L., Manion L., and Morrison K. (2000). Research methods in education. 5th ed. Routledge Falmer 11 New Fetter Lane, London EC4P 4EE ISBN 0-415-19541-1

Cole, M. (1996). Cultural Psychology. Cambridge, MA: Harvard University Press.

Creswell, J. W. (1994). Research Design: Qualitative \& Quantitative Approaches. Thousand Oaks, Calif.: Sage Publications.

Crotty M (1998). The foundations of social research: Meaning and perceptions in the research process. Sydney, Allen \& Unwin Pty Ltd; 1998.

De Grip, A., (2015). “The importance of informal learning at work." IZA World of labour. Online at:http://wol.iza.org/articles/importance-of-informal-learning-at-work.

ETF (2006).Reforming Technical Vocational Education and Training in the Middle East and North Africa: Experiences and Challenges": European Training Foundation 2006, Luxembourg ISBN $92-$ 9157-457-0

HalliDay-Wynes. S. \& Beddie, F. (2009). Informal learning at a glance, NCVER, Adelaide. https://unevoc.unesco.org/wtdb/worldtvetdatabase_uga_en.pdf.

ILO, (2012) Upgrading informal apprenticeship: a resource guide for Africa; International Labour 
Exploring the Effectiveness of Informal Apprenticeship in a Community of Practice: A Case Study of Katwe, Kampala-Uganda

Office, Skills and Employability Department. Geneva: ILO, 2012 ISBN: 9789221257769; 9789221257776 (web pdf).

Johanson, R. \& Adams, A.V. (2004). Skills development in Sub-Saharan Africa. Washington, DC: World Bank, Regional and Sectoral Studies.

John-steiner, V. \& Mahn, H. (1996): Sociocultural approaches to learning and development: A Vygotskian Framework, Educational Psychologist 31 (314), 191-206. University of Mexico.

Kitubi M. (2019). Education ministry roots for certified workers. New-vision newspaper 21st February 2019, Kampala-Uganda.

Kvale, S. (1996) Interviews. London: Sage Publications.

Lave, J. and E. Wenger, (1991). Situated Learning: Legitimate Peripheral Participation. Cambridge University Press.

Lule J. \& Nambooze J., M. (2006). The Hidden Wisdom of the Baganda: Amagezi g'Omuganda Amakusike (1908-2004). Arlington, Va.: Humbolt \& Hartmann, Inc.

Maclean, R. and Wilson, (2009). Issues, extracted on 24th July 2018 from http://www.springer.com/education+\&+language/book/978-1-4020-5280-4

Misko, J. (2008). Combining formal, non-formal and informal learning for workforce development. Australian Industry Group, NCVER. Adelaide

Mjelde, L. (1993). Apprenticeship: From Practice to Theory and Back Again. Joensuu, Finland: University of Joensuu Press.

Neuman, W. Lawrence. (2007). Basics of Social research, Qualitative and Quantitative approaches, 2th ed. Boston: Allyn and Bacon.

Nilsson, L. (2011). Vocational Education. A Historical Analysis: Vocational Didactics. Sweden: University of Goteborg.

Odiya,J. N. (2009).Scholarly Writing: Research Proposals and Report in APA or MLA publication style, Makerere University, Kampala.

Savery, J. \& Duffy, T. (1995). Problem Based Learning: An instructional model and its constructivist framework. Educational Technology, 35(31-38). 
Exploring the Effectiveness of Informal Apprenticeship in a Community of Practice: A Case Study of Katwe, Kampala-Uganda

Schugurensky, D. (2000). The forms of informal learning: Towards a conceptualization of the field.

New Approaches to Lifelong Learning. Working Paper No.19, University of Toronto, 252 Bloor St. West, Toronto, ON, M5S 1V6.

Wenger, E., and Snyder, W. (2000). "Communities of Practice: The Organizational Frontier." Harvard Business Review, Jan.-Feb., 2000, 139-145.

Wikipedia.org/wiki/Katwe. Retrieved 24th July, 2018

Wilson, S. M. and Peterson, P. L. (2006): Theories of Learning and Teaching. What Do They Mean for Educators? National Education Association 1201 16th Street, N. W. Washington, DC 200363290. 